Journal for ImmunoTherapy of Cancer Perret R. T-cell intrinsic Toll-like receptor signaling: implications for cancer immunotherapy and CAR T-cells. Journal for ImmunoTherapy of Cancer 2021;9:e003065. doi:10.1136/ jitc-2021-003065

Accepted 25 September 2021

Check for updates

(C) Author(s) (or their employer(s)) 2021. Re-use permitted under CC BY-NC. No commercial re-use. See rights and permissions. Published by BMJ.

${ }^{1}$ Cancer Immunotherapy Programme, Malaghan Institute of Medical Research, Wellington, New Zealand

${ }^{2}$ Department of Pathology \& Molecular Medicine, University of Otago, Wellington, Wellington, New Zealand

${ }^{3}$ Wellington Blood \& Cancer Centre, Capital and Coast District Health Board, Wellington, New Zealand

Correspondence to

Dr Rachel Perret;

rperret@malaghan.org.nz

\title{
T-cell intrinsic Toll-like receptor signaling: implications for cancer immunotherapy and CAR T-cells
}

\author{
Yasmin Nouri, ${ }^{1}$ Robert Weinkove, ${ }^{1,2,3}$ Rachel Perret (D) ${ }^{1}$
}

\begin{abstract}
Toll-like receptors (TLRs) are evolutionarily conserved molecules that specifically recognize common microbial patterns, and have a critical role in innate and adaptive immunity. Although TLRs are highly expressed by innate immune cells, particularly antigen-presenting cells, the very first report of a human TLR also described its expression and function within T-cells. Gene knock-out models and adoptive cell transfer studies have since confirmed that TLRs function as important costimulatory and regulatory molecules within T-cells themselves. By acting directly on T-cells, TLR agonists can enhance cytokine production by activated T-cells, increase T-cell sensitivity to T-cell receptor stimulation, promote longlived T-cell memory, and reduce the suppressive activity of regulatory T-cells. Direct stimulation of T-cell intrinsic TLRs may be a relevant mechanism of action of TLR ligands currently under clinical investigation as cancer immunotherapies. Finally, chimeric antigen receptor (CAR) T-cells afford a new opportunity to specifically exploit T-cell intrinsic TLR function. This can be achieved by expressing TLR signaling domains, or domains from their signaling partner myeloid differentiation primary response 88 (MyD88), within or alongside the CAR. This review summarizes the expression and function of TLRs within T-cells, and explores the relevance of T-cell intrinsic TLR expression to the benefits and risks of TLR-stimulating cancer immunotherapies, including CAR T-cells.
\end{abstract}

\section{INTRODUCTION}

A link between microbial toxins and regression of cancers has long been described. In the late 19th century, Coley observed that repeated local administration of bacterial toxins led to regression of cancers in some patients. $^{1}$ Several decades later, BCG, an attenuated Mycobacterium bovis strain used as a tuberculosis vaccine, was found to elicit an antitumor effect, ${ }^{2}$ and remains in routine clinical use as an immunotherapy for bladder cancer. ${ }^{3}$ On rare occasions, leukemias spontaneously enter remission following bacterial or fungal infection, possibly related to an exuberant innate immune response elicited by sepsis. ${ }^{4}$

Janeway proposed that evolutionarily conserved 'pattern recognition receptors'
(PRRs) recognizing common microbial characteristics are critical to immunological discrimination between 'self' and 'non-self'. Importantly, he hypothesized that these PRRs are expressed on T-cells themselves, and that both PRR and T-cell receptor (TCR) stimulation may be important for full protective immunity. ${ }^{5}$ Medzhitov et al later detected mRNA encoding the gene we now refer to as Toll-like receptor 4 (TLR4), the archetypal PRR, within human T-cells, and found that a chimeric TLR4 construct resulted in activation of nuclear factor kappa B (NF-kB) within a human T-cell line. ${ }^{6}$ Ten human TLRs are now recognized, and their expression across a broad range of tissues and cell types described. $^{7}$

TLR ligands are important vaccine adjuvants, acting by binding to TLRs expressed on antigen-presenting cells (APCs), and resulting in APC activation, enhanced antigen presentation to T-cells and B-cells, and provision of costimulatory signals $^{8}$ (figure 1A). Although recognized in the earliest report of human TLR expression, the role of T-cell-intrinsic TLRs is often overlooked. ${ }^{9}$ However, when the role of TLR expression on APCs versus T-cells is disentangled using knockout mouse models and T-cell transfer, it becomes evident that T-cell intrinsic expression of at least some TLRs is essential for full protective immunity, as Janeway had predicted (figure 1B). ${ }^{5}$ The distinction between APC-mediated TLR activity and T-cell intrinsic TLR activity in different $\mathrm{T}$ cell subsets is depicted in figure 1 . It should be noted that in an immune response to infection, both mechanisms are likely to be active.

Cancer immunotherapies that exploit TLR signaling are in clinical development. Agonists for TLRs including TLR 2, 3, 4, 7, 8 and 9 have been heralded as promising immunotherapeutics for their capacity to stimulate T-cell immunity, both as monotherapies for cancer, and in conjunction 


\section{A APC-mediated TLR activity}

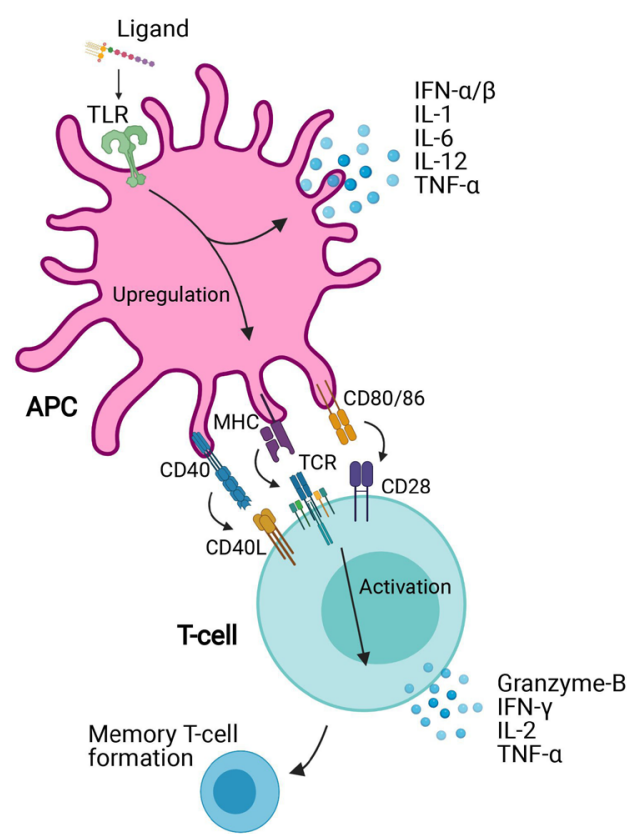

B T-cell intrinsic TLR activity

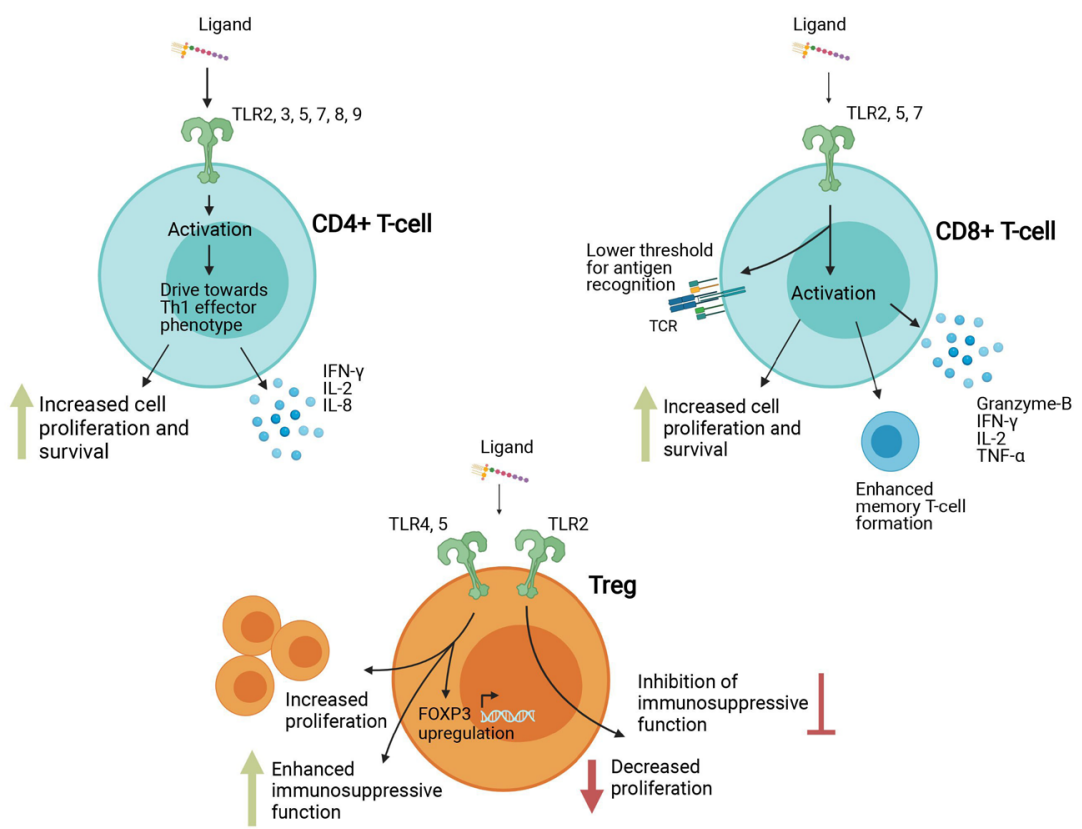

Figure 1 APC-mediated and T-cell intrinsic TLR activity. (A) TLR ligands can activate T-cells indirectly via APCs, where after ligand binding, TLR signaling via NF-kB induces an upregulation of MHC, costimulatory receptors, and proinflammatory cytokines. (B) TLR ligands can also induce T-cell activation directly via TLR molecules expressed on the T-cell surface. In CD4 ${ }^{+}$ and $\mathrm{CD}^{+}$effector T-cells, this activation is characterized by proinflammatory cytokines, memory T-cell formation, enhanced sensitivity to antigens and suppression of regulatory T-cells. In regulatory T-cells, different TLR ligands can have contrasting effects, either enhancing or suppressing their function. These different mechanisms, APC-mediated and T-cell intrinsic, likely work in concert in response to systemic TLR ligand exposure. The T-cell intrinsic pathway can be specifically exploited in T-cell mediated treatments such as adoptive cell transfers. APCs, antigen-presenting cells; IL-1, interleukin 1; MHC, major histocompatibility complex; NF-kB, nuclear factor kappa B; TLR, Toll-like receptor; TNF $\alpha$, tumor necrosis factor- $\alpha$.

with other treatment modalities, such as radiotherapy, chemotherapy or checkpoint inhibitors. ${ }^{10}$ More recently, TLR signaling domains and their downstream signaling adaptor myeloid differentiation primary response 88 (MyD88) have been incorporated into investigational chimeric antigen receptor (CAR) T-cells, providing the opportunity to specifically activate TLR signaling within tumor-recognizing T-cells. ${ }^{11-15}$

This review summaries the expression of TLR molecules by T-cell subsets, and explores their costimulatory, activating and regulatory functions. The relevance of this to cancer immunotherapies that exploit TLR signaling is discussed.

\section{INTRODUCTION TO THE TLR FAMILY}

The interleukin 1 receptor (IL-1R)/TLR superfamily is a group of cell surface receptors that play a crucial role in inflammation and disease. ${ }^{16}$ They are type I integral membrane receptors, located on the cell surface and within endosomes in both vertebrates and invertebrates. ${ }^{17}$ Originally discovered in Drosophila melanogaster as the transmembrane receptor Toll, ${ }^{18}$ a mammalian homologue was subsequently identified and defined as a TLR. ${ }^{6}$ Several more family members have since been discovered in mammals; to date 10 TLR genes have been identified in humans (TLR1-TLR10, figure 2) and thirteen in mice (TLR1-TLR13). Only twelve of the mouse TLRs are functionally expressed, as the murine TLR10 gene homolog has been disrupted by a retrovirus, resulting in an inactive pseudogene. ${ }^{19}$

TLR proteins are PRRs, which recognize pathogen associated molecular patterns (PAMPs) or endogenous damage associated molecular patterns and initiate immune responses. This results in the activation of downstream proinflammatory transcription factors such as NF- $\mathrm{kB}$ and interferon (IFN) regulatory factors ${ }^{20}$ (figure 2). All TLRs are composed of three parts: a leucine-rich N-terminal ligand binding domain, a singlepass transmembrane domain and a conserved C-terminal intracellular toll/IL-1R (TIR) signaling domain, which interacts with various adaptor proteins, primarily MyD88. ${ }^{8}$ TLRs are expressed at varying levels in many different cell types, both immune and non-immune, although most cells express only a subset of TLRs, and often at low levels. Hematopoietically derived sentinel cells, such as macrophages, neutrophils, and dendritic cells, express virtually all TLRs at relatively high levels, with some variation between cell subsets. ${ }^{21}$ For this reason, TLRs are traditionally associated with innate immune cells. 


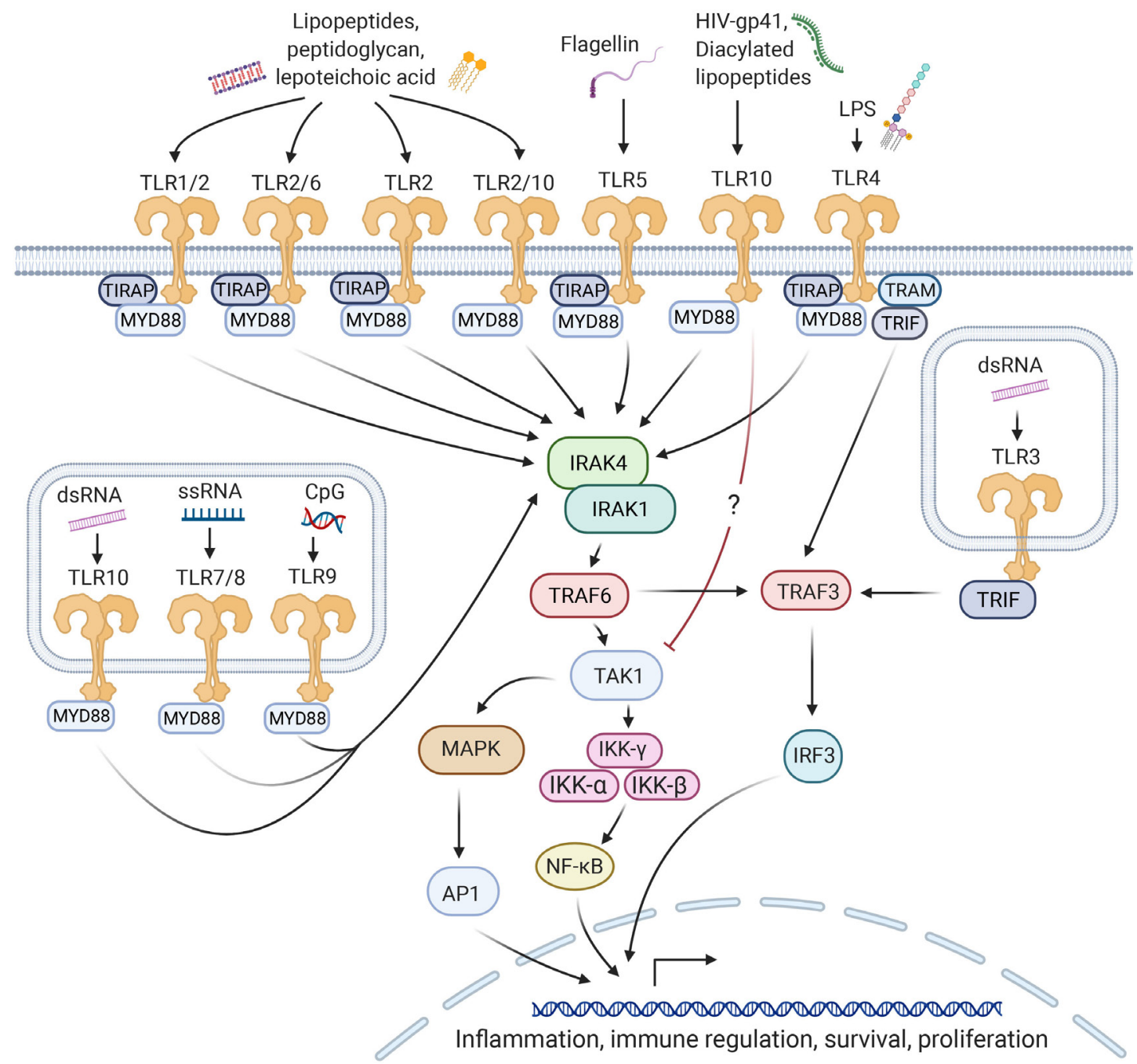

Figure 2 Classical TLR signaling pathways in human innate immune cells. TLR molecules can signal through MyD88dependent and independent pathways. In the MyD88-dependent pathway, activation of proinflammatory transcription factors AP1 and NF-kB is induced via IRAK1/4, TRAF6 and TAK1. In the MyD88-independent pathway, the adaptor molecule TRIF initiates signaling via TRAF3 and IRF, also resulting in the induction of proinflammatory gene transcription. AP1, activator protein 1; IRAK, IL-1R-associated kinase; IRF, interferon-regulatory factor; LPS, lipopolysaccharide; MyD88, myeloid Differentiation Primary Response 88; NF-kB, nuclear factor kappa B; TAK1, transforming growth factor- $\beta$-activated kinase-1; TIRAP, toll-IL 1 receptor domain containing adaptor protein; TLR, toll-like receptor; TRAF, tumor necrosis factor receptor-activated factor; TRAM, TRIF-related adaptor molecule; TRIF, toll/IL-1R domain-containing adaptor-inducing IFN- $\beta$.

\section{Cell surface receptors}

TLR1, 2, 4, 5 and 6, all located on the cell surface, specialize in the detection of ligands in the extracellular space, contributing to self/non-self-discrimination through recognition of microbially derived molecules. TLR1 forms a functional heterodimer with TLR2 to recognize triacylated lipopeptides from Gram-positive bacterial products, and TLR2 recognizes a wide range of structurally diverse PAMPs from bacteria, yeast, fungi, parasites and viruses. ${ }^{22}$ TLR2 ligands include lipopeptides from a variety of pathogens, and peptidoglycan and lipoteichoic acid from Gram-positive bacteria. ${ }^{8}$ Depending on the PAMP ligand, TLR2 can function as a homodimer or heterodimerize with TLR1, TLR6, or other non-TLR molecules. ${ }^{23}$ TLR4 was the first mammalian TLR identified. ${ }^{6}$ It recognizes lipopolysaccharide (LPS), a component of Gram-negative bacteria outer membranes. ${ }^{24}{ }^{25}$
TLR5 responds to flagellin, which is produced by virtually all Gram-negative and Gram-positive bacteria. ${ }^{26}$ TLR6 forms a functional heterodimer with TLR2 to recognize diacylated lipopeptides from gram-positive bacteria, mycoplasma, fungi and some viruses. ${ }^{22}$ Until relatively recently, TLR10 was the only human TLR without a known ligand or biological function. It has since been discovered that TLR10 is a modulatory receptor with an inhibitory role, working through complex mechanisms that are not yet fully understood, but that include forming heterodimers with TLR2. ${ }^{27}$

\section{Intracellular receptors}

TLR3, 7, 8, and 9 are located intracellularly on the surface of endosomes and lysosomes, their ligand binding domains projected into the interior of the organelles. The ligands that they recognize, primarily viral nucleic acids, 
are not in all cases unique to microbes. As such, the self/ non-self-discrimination for these TLRs is mediated by the location of their ligands rather than their molecular nature. ${ }^{28}$ Viral, but not host, nucleic acids are located in cell endosomes/lysosomes. These are accessible to intracellular TLRs through processes such as autophagy and intracellular compartment fusion. ${ }^{29}{ }^{30}$ TLR3 responds to double-stranded RNA, ${ }^{31}$ and TLR7 and TLR8 are both activated by single-stranded RNA from viruses. ${ }^{32}$ TLR9 recognizes unmethylated CpG motifs that are present in bacterial DNA. ${ }^{33}$ TLR11 and 12, two endosomal TLRs unique to murine species, have recently been shown to be activated by the actin-binding protein profilin, which is produced by the parasite Toxoplasma gondii. ${ }^{34}{ }^{35}$ TLR11 is also capable of activation via flagellin produced by Salmonella and Escherichia coli. ${ }^{36}$ TLR13, the final murine TLR, is present on endosomal surfaces and is activated by an unmethylated motif in bacterial RNA. ${ }^{37}$

\section{TLR SIGNALING PATHWAYS}

TLR signaling pathways in mammals are partly homologous to those of the IL-1R family, with both pathways interacting with the adaptor molecule MyD88 8 (figure 2). For signaling to occur, the TLR must either homodimerize or heterodimerize in order for the protein to undergo the conformational changes required for adaptor molecule binding. ${ }^{38}$ TLRs transmit a signal through their TIR, initiating a signaling cascade that is MyD88 dependent for all TLRs except TLR3. Some molecules, such as the adaptor Toll-IL-1R domain containing adaptor protein (TIRAP), are only involved in the signaling pathways of certain TLRs. ${ }^{39}$

After binding to the TLR TIR, MyD88 recruits the serine/threonine kinases IL-1R-associated kinases (IRAKs), primarily IRAK4 and IRAK1, which interact with tumor necrosis factor receptor-activated factor 6 (TRAF6) on phosphorylation. ${ }^{40}$ This interaction initiates distinct signaling pathways, resulting in the activation of proinflammatory transcription factors, NF-kB and/or activator protein $1(\mathrm{AP} 1) .^{20}$

TLR3, the only TLR to signal in a MyD88-independent manner, instead recruits the adaptor molecule Toll/ IL-1R domain-containing adaptor-inducing IFN- $\beta$ (TRIF) to its TIR domain. ${ }^{41}$ TLR4 is able to signal through both MyD88- and TRIF-dependent pathways, the latter pathway involving the TRIF-related adaptor molecule (TRAM), which interacts with TRIF exclusively in the TLR4 pathway. ${ }^{42}$ It is likely that differences in the signaling molecules recruited contribute to the variations in functional immune responses induced by different TLR ligands, alongside other characteristics such as cell subset-specific TLR expression patterns and spatial localization of TLRs. For example, the 'smooth' and 'rough' variants of LPS can initiate different signaling cascades-either MyD88or TRIF-dependent-allowing cells to respond differentially to bacteria containing different LPSs. ${ }^{43}$

Canonical TLR signaling pathways have principally been studied in innate cells due to their relatively high
Table 1 Expression and function of TLR molecules in murine and human $T$ lymphocytes

\begin{tabular}{|c|c|c|c|c|}
\hline \multirow[b]{2}{*}{ TLR } & \multicolumn{2}{|c|}{ Murine ${ }^{55-60}$} & \multicolumn{2}{|c|}{ Human $^{47-54}$} \\
\hline & CD4 & CD8 & CD4 & CD8 \\
\hline 1 & - & 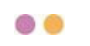 & - & O \\
\hline 2 & $\bullet \bullet$ & $\bullet$ & - & $\bullet \bullet$ \\
\hline 3 & $\bullet \bullet$ & O & - & $\bullet \bullet$ \\
\hline 4 & $\bullet \bullet$ & O & - & $\bullet \bullet$ \\
\hline 5 & - & O & - & $\bullet \bullet$ \\
\hline 6 & - & 0 & $\mathrm{O}$ & O \\
\hline 7 & - & $\bullet$ & - & O \\
\hline 8 & - & O & $\mathrm{O}$ & O \\
\hline 9 & $\bullet \bullet$ & - & - & 0 \\
\hline
\end{tabular}

O Not detected.

- mRNA expression.

Protein expression.

- Functional evidence.

TLR, Toll-like receptor.

levels of TLR expression. There are fewer reports of the pathways involved in TLR signaling within T-cells, which express lower levels of certain TLRs, although limited information suggests that signaling pathways may differ. For example, it has been established that within APCs, signaling in response to the TLR2 ligand Pam3CSK4 requires the recruitment of MyD88, TIRAP and IRAK4. However, in T-cells from either MyD88- or IRAK4-deficient mice, TLR2 activation can elicit a partial immune response via c-Jun N-terminal kinase, p38 and an unknown adaptor molecule, suggesting an alternative TLR2 signaling pathway in T-cells. ${ }^{44}$ It has also been shown that in T-cells, the TLR2 signaling pathway converges with TCR signaling at the level of Erk1/Erk2 and Akt activation, to enhance TCR signal-dependent functions. ${ }^{45}$

\section{TLR EXPRESSION WITHIN T-CELLS}

Although expressed particularly highly by APCs, TLRs are also expressed by a wide range of immune and nonimmune cells, including B-cells, T-cells, NK cells, epithelial cells and fibroblasts. ${ }^{76}$ T-cell intrinsic TLR expression has been well reported, but studies vary widely in terms of species and mouse strain, analysis of $\mathrm{CD} 4^{+}$versus $\mathrm{CD} 8^{+}$ T-cell subsets, T-cell activation status, memory vs naïve phenotype, and mRNA vs protein analysis, etc. Table 1 summarizes the T-cell intrinsic TLR expression data from literature cited in this review. A filled symbol for mRNA, protein, or functional data indicates that evidence of these forms of TLR expression has been found in the T-cell subsets examined. An empty symbol indicates that no TLR expression was detected in the various studies cited here, although further research may update this.

In humans, TLR expression has been identified in T-cells in several research studies, although there is 
variation between reported findings. This may relate in part to between-donor variation, and in part due to technical differences between studies. Several studies have found that human $\mathrm{CD} 4^{+}$T-cells express mRNA for almost all TLRs at varying levels ${ }^{47-49}$ while activated $\mathrm{CD} 8^{+} \mathrm{T}$-cells express higher levels of TLR2, 3 and $5,{ }^{48-53}$ and in a rheumatoid arthritis setting, TLR $4 .^{54}$

The expression of TLR mRNA and proteins by murine $\mathrm{CD}^{+}{ }^{+}$T-cells has been explored in some detail; mRNA encoding TLRs can be found at varying levels both naïve and activated CD $8^{+}$T-cells. ${ }^{55}$ TLR surface expression and function, however, appears to be restricted to TLR2 and its heterodimer partners, TLR1 and TLR6. Activation of $\mathrm{CD}^{+} \mathrm{T}$-cells is associated with significant enhancement of surface TLR2 expression and function. ${ }^{56}$ Within murine $\mathrm{CD}^{+}$T-cells, mRNA of virtually all TLRs is expressed, however the difference in expression between cell subsets is significant. ${ }^{57}$ For example, it has been shown that antigen experienced Tregs express mRNA for TLR1, 2, $4,5,6,7$, and 8 at varying but detectable levels, whereas naïve Tregs express significantly lower levels of TLR4, 5 , 7 , and 8 , but maintain high levels of TLR1, 2 , and $6 .{ }^{58}$ Protein expression is relatively broad,$^{59}$ although as for $\mathrm{CD}^{+}{ }^{+}$T-cells, TLR2 surface expression is significantly upregulated on $\mathrm{CD} 4^{+}$T-cell activation. ${ }^{60}$

The differences in surface expression of TLR molecules within T-cells is not the only determining factor of TLR function within that cell subtype; the expression of downstream molecules in the TLR pathways is equally important in determining function. For example, it has recently been shown that differences in the expression of TIRAP, which is induced by TCR or IL-2R activation and regulated by mammalian target of rapamycin complex 1 (mTOR), may underpin the variation in responses to TLR2 ligands between naïve and antigen-experienced T-cells. ${ }^{61}$

Together, these reports indicate broad expression of TLR mRNA in T-cells of both mice and humans, with protein expression and function restricted to a narrower range of predominantly cell surface-expressed TLRs, particularly in $\mathrm{CD}^{+} \mathrm{T}$-cells. It is notable that the majority of studies report differences between mRNA and protein expression, emphasizing the importance of protein-level and functional analyses alongside mRNA quantitation when exploring the role of TLRs in T-cell subsets.

\section{FUNCTIONS OF T-CELL INTRINSIC TLRS}

Several functional roles for T-cell-intrinsic TLRs have been established: enhancement of T-cell effector function; enhancement of T-cell proliferation and survival; and modification of regulatory function.

\section{TLRs as costimulatory molecules}

Cosignaling molecules, both stimulatory and inhibitory, have a crucial role in the regulation of T-cell activation, differentiation, cytotoxic function and memory formation. Following peptide/Major Histocompatibility
Complex (MHC) binding, a balance between costimulatory signals received via CD28 and ICOS and inhibitory signals from PD-1 and CTLA4 will determine the magnitude and nature of the T-cell response. ${ }^{62}$ In addition to the conventional cosignaling molecules, a number of alternative pathways have been identified. One of these non-classical signaling routes is through TLR pathwaysthe engagement of which has been repeatedly shown to enhance the activation, effector function and memory formation of T-cells.

\section{TLR costimulation of $\mathrm{CD} 4^{+} \mathrm{T}$-cells}

Many studies have reported TLR costimulatory activity in $\mathrm{CD}^{+} \mathrm{T}$ cells, predominantly focusing on the effects of TLR2. This is in large part due to the robust evidence that surface expression of TLR2 in human T-cells is enhanced by TCR activation. ${ }^{51}$ The majority of studies report that TLR2 costimulation directs T-cells toward a Th1 effector phenotype, although there are several reports in the literature of TLR2 ligands driving human and mouse T-cells toward a $\mathrm{Th} 9^{63}$ or $\mathrm{Th} 17^{6465}$ phenotype in some contexts.

In naïve human $\mathrm{CD} 4^{+} \mathrm{T}$-cells, both adult and neonatal, TLR2 engagement has been shown to enhance the production of IL-2 and key Th1 cytokines, while simultaneously reducing the production of suppressive IL-10. ${ }^{66}$ This effect was more pronounced in neonatal cells, enabling them to produce levels of IFN- $\gamma$ and IL-2 equivalent to adult cells. This points to the potential of TLR2 ligands as neonatal vaccine adjuvants. ${ }^{66}$ In one study of activated human $\mathrm{CD} 4^{+} \mathrm{T}$-cells, elevated levels of Th1 cytokines were produced in response to the TLR2 ligand Pam3CSK4. ${ }^{51}$ Furthermore, it was shown that $\mathrm{CD}^{+}$memory $\left(\mathrm{CD} 45 \mathrm{RO}^{+}\right)$T-cells produced higher levels of cytokines in response to TLR2 ligands than did $\mathrm{CD} 4^{+}$ naïve (CD45RA ${ }^{+}$) T-cells. Interestingly, it was also shown that even without TCR engagement, TLR2 activation along with IL-2 or IL-15 stimulation increased proliferation and IFN- $\gamma$ production in memory T-cells in vitro. This suggests a TCR-independent role for TLR2 in T-cell memory formation or maintenance. In the absence of APCs, the TLR2 ligand Pam3CSK4, the TLR5 ligand flagellin, and the TLR7/8 ligand R-848, can all enhance proliferation and the production of IFN- $\gamma$, IL-8, and IL-10 in human $\mathrm{CD}^{+} \mathrm{T}$-cells. This can be both TCR-dependent stimulation (anti-CD3 $\mathrm{mAb}$ ) and TCR-independent (antiCD2 mAb or IL-2) ${ }^{49}$ This effect is enhanced in memory T-cells compared with naïve T-cells, and was not seen with ligands for TLR3 (poly I:C) or TLR4 (LPS).

In mice, there is also abundant evidence of TLR activity in $\mathrm{CD}^{+} \mathrm{T}$ cells. In one report, TCR-independent TLR2 engagement on mouse Th1 effector cells resulted in IFN-y production, cell proliferation and survival even in the absence of TCR stimulation. This suggests that TLR2 engagement on cells has the potential to directly trigger effector function. ${ }^{44}$ TLR2 engagement on chronically activated mouse Th1 cells has also been shown to play a role in the reinvigoration of exhausted T-cells during chronic infection. ${ }^{67}$ On engagement of TLR2 on chronically 
activated Th1 cells, $\mathrm{CD} 4^{+} \mathrm{T}$-cells significantly alter expression of T-bet, IFN- $\gamma$, IL-2 and the antiapoptotic molecule Bcl-2, reduce expression of PD-1 and Lag-3, and exhibit an enhanced ability to activate B-cells. Ultimately, these observations resulted in reduced lung pathology and improved disease control in models of chronic tuberculosis infection. Interestingly, in one paper looking at activated $\mathrm{CD}_{4}^{+}$murine T-cells, it was reported that treatment with the TLR3 ligand poly I:C and the TLR9 ligand CpG directly enhanced T-cell survival, an effect which was not seen with ligands for TLR4, or with an alternative TLR2 ligand peptidoglycan, ${ }^{57}$ rather than the more conventional Pam3CSK4. TLR2 expression was not observed in this study, in contrast with several other papers reporting increased TLR2 in T cells following activation.

\section{TLR costimulation of $\mathrm{CD} 8^{+} \mathrm{T}$-cells}

As well as providing $\mathrm{CD}^{+}$T-cell costimulation, TLR engagement, especially TLR2, can enhance the cytotoxic activity of $\mathrm{CD}^{+}$T-cells. In cord blood-derived human CD8 ${ }^{+}$T-cells, the TLR2 ligand Pam3CSK4, as well as the TLR5 ligand flagellin, significantly enhanced proliferation, memory formation and cytokine production (IL-2, IFN- $\gamma$, and TNF- $\alpha$ ) in the presence of TCR stimulation. ${ }^{68}$ This effect was enhanced when both ligands were used in combination. Additionally, TLR3 on the surface of human $\mathrm{CD}^{+}$effector T-cells can act as a functional costimulatory molecule by increasing production of IFN- $\gamma^{53}$

There are also several reports of TLR costimulation of murine $\mathrm{CD}^{+} \mathrm{T}$ cells. For example, in $\mathrm{CD}^{+}{ }^{+} \mathrm{T}$-cells from TCR-transgenic mice, TLR2 engagement via Pam3CSK4 resulted in increased cell proliferation and survival, increased IFN- $\gamma$ production and granzyme-B secretion. ${ }^{55}$ In addition to this, TLR2 engagement can enhance effector functions of the $\mathrm{CD} 8^{+}$T-cells by lowering the threshold of activation for additional costimulatory signals from APCs. Moreover, TLR2 activation on $\mathrm{CD} 8^{+}$ T-cells, lowers the antigen density required for optimal activation. ${ }^{69}$ This resulted in the proliferation of effector cells even in environments of low antigen density, ultimately leading to the generation of functional memory T-cells in response to a suboptimal TCR signal and only partial activation. The mechanism behind the lowering of antigen threshold needed for activation has been in part attributed to TLR2 signaling synergising with the TCR to prolong the $t_{1 / 2}$ of IFN-y mRNA. ${ }^{70}$ These results have been reaffirmed with the use of TLR2 ${ }^{-/}$mice, which have a decreased frequency of $\mathrm{CD}^{+}$memory T-cells in comparison to wildtype (WT) mice, further suggesting that TLR2 has a role in the maintenance and formation of memory T-cells. ${ }^{69}$ When further probed, this was shown to work through a TLR2-dependent mechanism, which increases the IL-7 induced proliferation of memory $\mathrm{CD}^{+}$ T-cells. In the context of viral infection, TLR2 signaling was shown to promote the survival of activated mouse $\mathrm{CD}^{+}{ }^{\text {T-cells. }}{ }^{71}$ Furthermore, cells lacking TLR2-MyD88 signaling exhibited a drastically reduced ability to differentiate into long-lived memory T-cells. A more recent study investigating the contribution of TLR7 stimulation to murine CD8 ${ }^{+}$T-cell functions found that the TLR7 ligand R-848 (Resiquimod) could enhance T-cell effector function in vitro, when in combination with CD3 activation. ${ }^{72}$ This occurs through activation of the MyD88/AktmTOR signaling pathway.

\section{TLRs as modulators of regulatory T-cell function}

Several independent studies have reported that stimulation of TLR2 in T-regulatory cells can dampen their immunosuppressive capabilities. In humans, both TLR2 ligand Pam3CSK4 and a TLR2/6 heterodimer ligand FSL-1 reduced the suppressive function of naïve $\left(\mathrm{CD} 4^{+} \mathrm{C}\right.$ D25 ${ }^{\text {high }}$ FOXP $3^{\text {low }} \mathrm{CD} 45 \mathrm{RA}^{+}$) and memory/effector $\left(\mathrm{CD} 4^{+} \mathrm{CD} 25^{\text {high }}\right.$ FOXP ${ }^{\text {high }}$ CD $\left.45 \mathrm{RA}^{-}\right)$Tregs, by skewing them toward a Th17 effector phenotype.$^{64}$ Another study found that engagement of TLR2 on human $\mathrm{CD} 4^{+} \mathrm{CD} 25^{+}$ Tregs caused a reduction in Treg-mediated suppression of responder T-cells. ${ }^{73}$ Conversely, a TLR5 ligand delivered with anti-CD3 activation enhanced suppressive activity and expression of the Treg-associated transcription factor FOXP3 in human $\mathrm{CD} 4^{+} \mathrm{CD} 25^{+} \mathrm{T}$ regulatory cells. ${ }^{50}$

A similar variability in TLR-mediated effects on Treg suppressive function has been observed in mice. The discovery that there are significantly fewer $\mathrm{CD} 4^{+} \mathrm{CD} 25^{+}$ Treg cells in TLR2 ${ }^{--}$mice compared with WT control mice was one of the first indications of a link between Tregs and TLR2. ${ }^{74}$ The TLR1/2 ligand Pam3CSK4, when combined with TCR stimulation, results in a temporary loss of the suppressive function of $\mathrm{CD} 4^{+} \mathrm{CD} 25^{+}$Tregs in vitro. ${ }^{75}$ The same effect was not seen with TLR4 or TLR9 ligands. Similar results were seen in another study of murine $\mathrm{CD} 4^{+} \mathrm{CD} 25^{+}$Tregs and $\mathrm{CD} 4^{+} \mathrm{CD} 25^{-}$effector T-cells, where Pam3CSK4 administration alongside CD3 activation resulted in a transient loss of suppressive activity by Tregs as well as effector T-cell resistance to the suppressive effect of Tregs. ${ }^{60}$ In contrast to the above studies, in $\mathrm{C} 57 \mathrm{BL} / 6$ mice, a subset of regulatory $\mathrm{CD} 45 \mathrm{RB}^{\text {low }} \mathrm{C}$ $\mathrm{D} 25^{+} \mathrm{CD} 4^{+}$T-cells exhibited enhanced suppressive abilities and proliferation after administration of the TLR4 ligand LPS. ${ }^{58}$

Together, these results provide evidence for a significant and sometimes crucial role for TLR signaling within T-cells. Direct activation of TLR molecules on T-cells can enhance their proliferation and effector function. The capacity of TLRs to enhance function of T-cells that typically exhibit suboptimal responses will be of interest in specific settings, such as the vaccination of neonates. ${ }^{6676}$ Moreover, the capacity of TLR2 stimulation to lower the TCR signal threshold for optimal T-cell activation may be exploited in settings of low antigen density, such as within some tumors. ${ }^{69}$ The variability in the response of T-regulatory cell subsets to different TLR ligands, observed in both humans and mice, is an important consideration in the development of therapeutics. Overall, the specific impact of TLR stimulation on T-cell subsets can be expected to vary by T-cell subset, by TLR agonist, and in varying immune contexts. 


\section{TLR AGONISTS AS CANCER IMMUNOTHERAPIES}

In the late 19th century, Coley observed that repeated administration of certain bacterial toxins produced a moderate antitumor effect in some patients. ${ }^{1}$ A closer look into Coley's toxins found that it was the polysaccharide fraction from the Serratia marcescens bacteria inducing tumor necrosis. ${ }^{77}$ We now define this component of the outer membrane of Gram-negative bacteria as LPS, a TLR4 agonist. Unfortunately, due to the toxicity of LPS, the tolerable dose is typically too low to induce a robust antitumor effect in patients with cancer, and therefore, is not a viable treatment, although it suggests there is potential for TLR activation in anticancer therapy. ${ }^{78}$ Much work has been done since to provide further insight into the anti-tumor effects of TLR ligands. ${ }^{78-81}$

BCG, an attenuated Mycobacterium bovis strain, was developed as a tuberculosis vaccine, however it was proposed relatively early on to have anticancer properties after an observation that administering it into tumors had a moderate anticancer effect. ${ }^{1}$ Almost a century on, this was confirmed in successful trials using BCG as a treatment for bladder cancer, ${ }^{82} 83$ and it is still used to this day. Peptidoglycan, an important component of the Mycobacterium cell wall and a TLR2/4 agonist, is thought to drive BCG's local anti-tumor effect through the induction of a substantial inflammatory response. ${ }^{78}$ Peptidoglycan potentiates the maturation of dendritic cells, leading to increased proinflammatory cytokine secretion and immune cell infiltration. ${ }^{84}$

The most well defined antitumor effect of TLRs is their ability to stimulate the adaptive immune system, either directly or via APCs, and enhance its ability to act against aberrantly expressed antigens present in cancers. So far, several TLR agonists, most notably those activating TLR2, 3, 4, 7, 8 and 9, have been heralded as promising novel immunotherapeutic agents due to their ability to initiate T-cell immunity, both as monotherapies and in conjunction with other treatments. ${ }^{1085}$ Agonists can also be delivered alongside antigen as vaccine adjuvants, for example by conjugating TLR ligands to antigenic peptides. ${ }^{86} 87$

In humans, both the TLR1/2 ligand Pam3CSK4 and the TLR7 ligand gardiquimod have been used as antitumor vaccine adjuvants to boost T-cell responses. These combinations have been shown to induce tumor-specific human CD8 + T cells with reduced PD-1 expression and improved anti-tumor activity in human xenograft mouse models. ${ }^{88}$ TLR agonists, including imiquimod (TLR7), CpG 7909 (TLR9) and Poly I:C (TLR3) have shown therapeutic potential in various cancers when administered locally as monotherapies, however, their use as systemic therapies are limited by toxicity. ${ }^{10}$

In mice, stimulation of TLR2 and/or TLR1/2 heterodimer in T-cells has shown recent promise as an anticancer therapy. In mouse models of lung carcinoma, leukemia and melanoma, systemic treatment with the TLR1/2 agonist bacterial lipoprotein
(BLP) leads to dose-dependent tumor regression and long-lasting protection against tumor re-challenge. ${ }^{89}$ Moreover, it was shown through the use of Severe Combined Immunodeficient (SCID) mice lacking T-cells or B-cells that this effect was at least partially mediated by T-cells themselves, as well as through TLRexpressing APCs. BLP reduced the suppressive function of $\mathrm{FOXP}^{+}$T-regulatory cells and enhanced the effector function of tumor specific T-cells. Systemic injection of BLP has also been shown to enhance the antitumor effects of adoptive T-cell therapy in a study of glioma-bearing mice. ${ }^{90}$ Results showed enhanced long-term survival and immune protection in comparison to mice receiving adoptive T-cell transfer without BLP. These effects were not seen when either TLR2mice or $\mathrm{TLR}^{-/}$transferred T-cells were used. This suggests that the full antitumor effect of BLP in this study requires TLR2 expression by both the T-cells themselves and by other immune cells in the tumor microenvironment.

In a different study, Pam3CSK4 stimulation of mouse cytotoxic $\mathrm{T}$ lymphocytes enhanced antitumor activity in a an ovalbumin-expressing mouse model of melanoma. ${ }^{91}$ Adoptive transfer of OT-1 (ovalbumin-specific $\mathrm{CD}^{+}$) T-cells followed by Pam3CSK4 injection resulted in an anti-tumor effect, whereas adoptive transfer of TLR2 ${ }^{-/}$ OT-1 T-cells plus Pam3CSK4 had a minimal anti-tumor effect. Another study reported that in TCR transgenic 'pmel' mice, TLR2-stimulated, melanoma gp100 antigentargeting CD8 T-cells responded to significantly lower tumor antigen levels and were more cytotoxic than TLR2 ${ }^{-}$ or MyD88 ${ }^{-/}$pmel T-cells. ${ }^{92}$ This enhanced antitumor activity was attributed to both increased effector function and increased survival of the T-cells.

Beyond the T-cell intrinsic effects of TLR signaling illustrated here, a recent review has described a broad pattern of TLR expression in human and mouse NK cells. TLR2, 3, 4, 5, 7 and 9 agonists can stimulate NK cell cytotoxicity and IFN- $\gamma$ production resulting in antitumor activity ${ }^{93}$ This combined body of evidence implicates NK cells, along with T-cells and APCs, in the response to TLRmediated cancer immunotherapies.

\section{Clinical trials}

As of August 2021, there were over 200 currently active or completed cancer-related clinical trials using TLR ligands, inhibitors or TLR signaling domains listed in the National Institutes of Health's National Clinical Trials (NCT) database. The vast majority of these trials target the TLR pathway in combination with other treatments such as radiotherapy and chemotherapy (NCT01421017), immune checkpoint inhibition (NCT02643303) and dendritic cell vaccines (NCT01204684). ${ }^{94-98}$ Listed in table 2 are late-stage clinical trials for various TLR ligands (completed phase 2 and above). While this list illustrates the vast number of existing clinical trials for TLR ligands as cancer therapies, it is by no means exhaustive. There are many phase 1 and early-stage phase 2 trials listed in 
Table 2 Phase 3 and completed phase 2 clinical trials targeting the TLR pathway for treatment of cancer

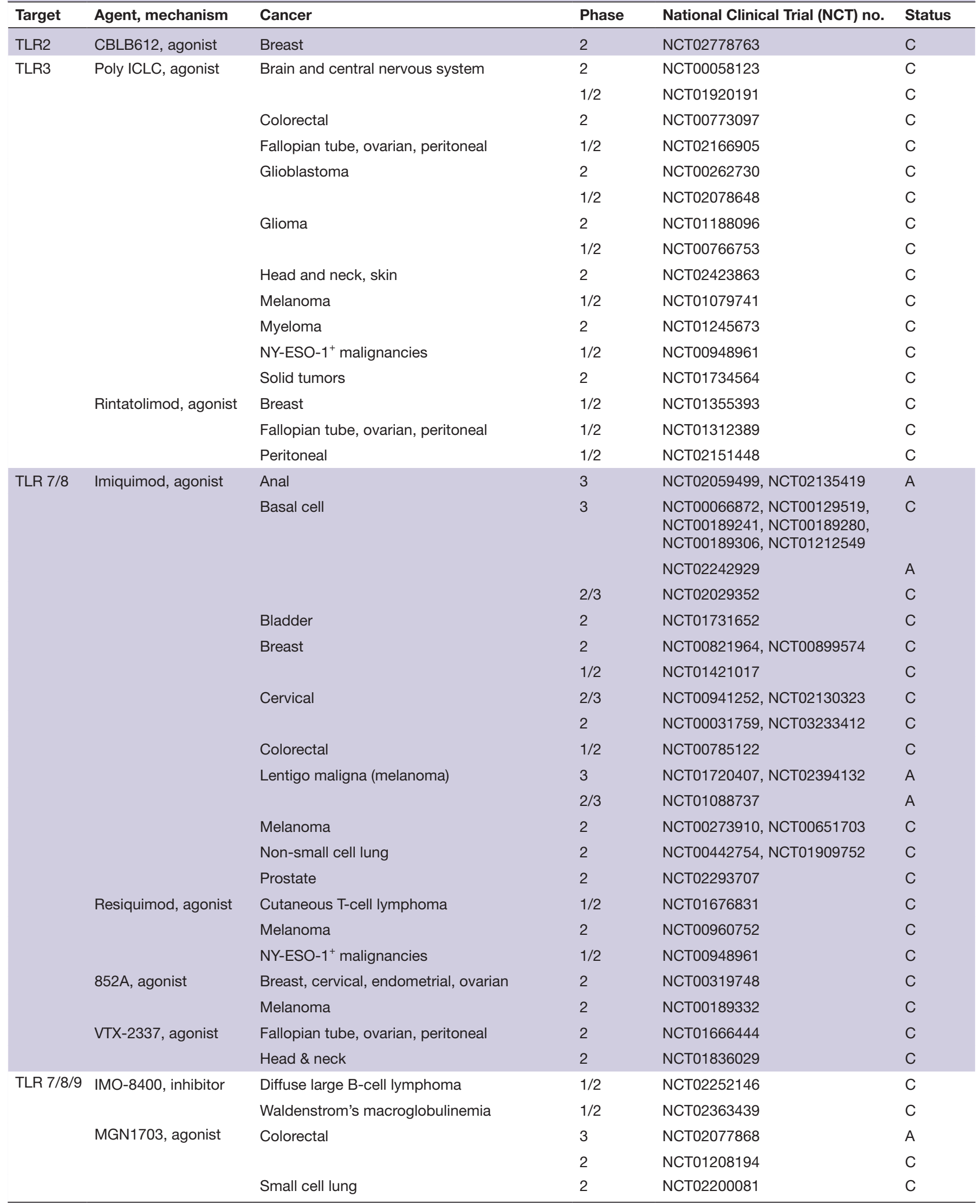


Table 2 Continued

\begin{tabular}{|c|c|c|c|c|c|}
\hline Target & Agent, mechanism & Cancer & Phase & National Clinical Trial (NCT) no. & Status \\
\hline \multirow[t]{8}{*}{ TLR9 } & \multirow[t]{6}{*}{ CPG 7909, agonist } & Breast & 2 & NCT00043394 & $\mathrm{C}$ \\
\hline & & & $1 / 2$ & NCT00031278 & C \\
\hline & & B-cell lymphoma & 2 & NCT00880581, NCT00490529 & $\mathrm{C}$ \\
\hline & & Melanoma & 2 & $\begin{array}{l}\text { NCT00070642, NCT00085189, } \\
\text { NCT01266603 }\end{array}$ & $\mathrm{C}$ \\
\hline & & Non-small cell lung & 2 & NCT00070629 & $\mathrm{C}$ \\
\hline & & Renal & $1 / 2$ & NCT00043407 & $\mathrm{C}$ \\
\hline & $\begin{array}{l}\text { EMD 1201081/IMO- } \\
\text { 2055, Agonist }\end{array}$ & Head and neck & 2 & NCT01040832 & $\mathrm{C}$ \\
\hline & SD-101, agonist & B-cell lymphoma & $1 / 2$ & NCT02254772 & $\mathrm{C}$ \\
\hline
\end{tabular}

Source: https://clinicaltrials.gov.

A, active trial; C, completed trial; no., number; NY-ESO-1, New York Esophageal Squamous Cell Carcinoma-1, tumor antigen; TLR, Toll-like receptor.

clinical trial registries that are currently active across all TLRs, for agonists and inhibitors listed below as well as other novel ligands.

The number of later-phase trials listed in table 2 highlights the keen interest in TLR ligands as cancer therapies. A major caution for the use of systemic TLR agonists is that although these compounds can result in direct and indirect T-cell activation, in certain circumstances, TLR activation may also promote tumor growth. ${ }^{99}$ Several studies have shown that not only is the expression of certain TLRs elevated in both human and mouse tumors, but that the activation of these TLRs can enhance tumor progression and worsen disease prognosis. ${ }^{100} 101$ TLR2 activation in particular has been shown to have a direct tumor-stimulating effect in certain malignancies, promoting tumor cell survival, proliferation and metastatic capabilities. It can also enhance resistance to chemotherapeutic agents through its activation of NF-אB. ${ }^{101-104}$ Similar results have been seen with TLR4 activation, where stimulation with LPS resulted in increased tumor cell survival, proliferation and metastatic potential. ${ }^{105} 106$ This effect was also observed with TLR5 and TLR9 agonists. ${ }^{107-109}$

Overall, there is strong evidence that administration of TLR agonists can have either a protumor or antitumor effect, depending on the ligand and the tumor type. Evidently, the tumor-stimulating effect is not driven by TLRs expressed on the T-cells, but rather by the TLRs expressed on the cancer cells themselves. As such, there is a substantial advantage to being able to exclusively harness TLR action on T-cells, without stimulating TLRs on the tumor cells. This holds particular potential with TLR2, which has immense T-cell activation potential, but can induce a protumor effect in various cancers.

\section{COSTIMULATION OF GENE-MODIFIED T-CELLS VIA TLR SIGNALING}

Gene-modified T-cells, expressing a specific TCR or CAR directed against a specific antigen, afford a unique opportunity to both redirect and to modify the function of T-cells. Tumor-specific CARs typically incorporate one or more costimulatory domains in the intracellular region of the construct, alongside the TCR signaling domain, CD3C. Costimulatory domains must be carefully considered, as different signaling proteins can change crucial functional aspects of the CAR T-cells with the same antigen-recognition domain, including their kinetics, cytotoxicity and safety profile. ${ }^{110}$ Although CAR costimulatory molecules have traditionally been confined to the immunoglobulin (Ig) superfamily members CD28 or ICOS, or the tumor necrosis factor receptor (TNFR) superfamily members, 4-1BB and OX40, TLR signaling domains may also represent useful costimulatory partners for $\operatorname{CD} 3 \zeta$. $^{11-13}$

In one study, the TLR adaptor molecule MyD88 was employed alongside CD40 in an inducible costimulatory complex consisting of a chemical inducer of dimerization binding domain, and coexpressed with a first-generation HER2-targeting CAR construct in T-cells. ${ }^{14}$ These inducible MyD88/CD40 CAR T-cells exhibited superior T-cell proliferation, cytokine production and tumor killing ability in comparison to second-generation CAR T-cells that did not contain the inducible MyD88/CD40 molecule both in vitro and in xenograft models. This same inducible system, adapted to target PSCA, is currently being used in a phase $1 / 2$ clinical trial (NCT02744287). Recently, work has been published on CD19- and CD123targeting MyD88/CD40 CAR T-cells, this time with the MyD88 and CD40 domains tethered to the CAR 
A $1928 T 2 \zeta$ Chimeric

Antigen Receptor
B CAR.MC.Z Chimeric Antigen Receptor
C CD8a:MyD88

coreceptor

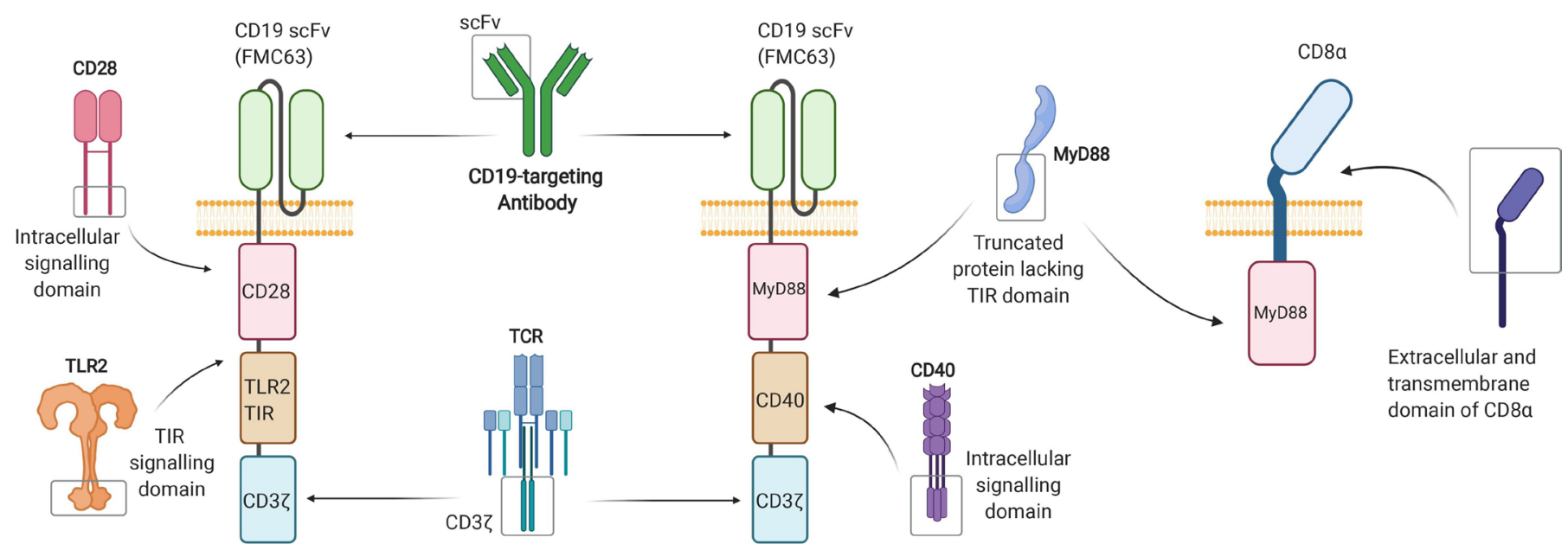

Figure 3 Depiction of CAR and coreceptor constructs utilizing the TLR signaling pathway. (A) Third-generation, CD19targeting, 1928T2z CAR construct incorporating the intracellular TIR signaling domain derived from TLR2, alongside the

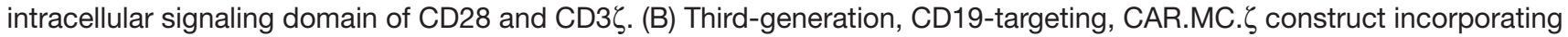
a truncated version of MyD88 lacking its TIR domain and the intracellular signaling portion of CD40 alongside CD3 . (C) CD8 $\alpha: M y D 88$, a synthetic coreceptor that fuses together the extracellular and transmembrane domains of CD8 $\alpha$ and the intermediate and death domains of MyD88. CAR, chimeric antigen receptor; MyD88, myeloid differentiation primary response 88; TIR, toll/interleukin-1 receptor; TLR, Toll-like receptor.

molecule $^{15}$ (figure 3B). These signaling domains have been shown to successfully enhance CAR T-cell proliferation in vivo.

Another study generated third generation CARs containing the TIR domain of TLR2 alongside CD28 and CD3 $\zeta$ : one targeting CD19 (1928zT2) and another targeting mesothelin (m28zT2). ${ }^{12}$ The CD19-targeting and mesothelin-targeting CARs harboring the TLR2 TIR domain displayed enhanced expansion, persistence and effector function both in vitro and in vivo compared with second generation CD28 signaling CARs with no TLR2 domain. In a phase I clinical trial (NCT02822326), one patient with relapsed B-cell ALL receiving a single dose of $5 \times 10^{4}$ cells $/ \mathrm{kg}$ of $1928 \mathrm{~T} 2 \mathrm{z}$ CAR T-cells experienced complete eradication of the leukemia. ${ }^{12}$ Subsequently, a further three patients diagnosed with relapsed or refractory ALL were treated with between $5 \times 10^{4}$ and $1 \times 10^{6} 1928 \mathrm{~T} 2 \mathrm{z}$ CAR $\mathrm{T}$ cells $/ \mathrm{kg}$ and achieved complete remission without serious adverse events. ${ }^{11}$ Building on these results, a phase I clinical trial using a 1928T2z CAR (figure 3A) to treat relapsed or refractory non-Hodgkin's B-cell lymphoma is currently being undertaken at our own center ('ENABLE', NCT04049513). ${ }^{13}$ Further research has recently been conducted with the aim of making these CAR T-cells more effective against solid malignancies. When engineered to secrete human IL-7 and CCL19, glypican-3-specific (g28T2z) and mesothelinspecific (m28T2z) CAR T-cells displayed enhanced tumor clearance in both xenograft models and a phase I clinical trial (NCT03198546). ${ }^{111}$
In addition to CARs, TLR pathway signaling domains are showing success in other synthetic T-cell stimulatory molecules. CD8 $\alpha$ :MyD88, a synthetic coreceptor that fuses together the extracellular and transmembrane domains of $\operatorname{CD} 8 \alpha$ and the intermediate and death domains of MyD88 (figure 3C), is being used as another way of activating the TLR signaling pathway in T-cells. ${ }^{112}$ On antigen binding, the $\mathrm{CD} 8 \alpha$ portion of the coreceptor interacts with the TCR and initiates TLR pathway activation through the fused MyD88 intracellular domain. This results in increased effector function and decreased exhaustion of the T-cells, which has been shown to provide an advantage against weak tumor antigenicity and suppressive tumor microenvironments.

The field of CAR-NK cells is growing rapidly, having shown early promise in research and clinical settings. ${ }^{113}$ Noting the impact of TLR agonists on NK cell function, CAR constructs containing TLR pathway signaling domains could also provide a functional advantage to CAR NK-cells, although this area of research is yet to be explored.

Benefits of T-cell and NK-cell intrinsic TLR signaling include enhanced proliferation and antitumor activity in response to lower levels of antigen. TLR signaling in CAR T-cells leads to qualitative improvement in phenotype and function, which may enable the use of lower doses of gene-modified T-cells for adoptive cell therapy. Restricting TLR signaling to the T-cells themselves avoids any potential growth-promoting impacts of TLR agonists on tumor and microenvironment. It should be noted 
that this approach is not without risk. Enhancement of T-cell cytokine production by TLR signals could plausibly present an increased risk of cytokine release syndrome, a key CAR T-cell toxicity. Furthermore, an activating point mutation of MYD 88 has been implicated as a driver mutation in some B-cell lymphomas, ${ }^{114} 115$ and a theoretical concern is that constitutive TLR signaling might carry a risk of malignant transformation of the gene-modified T-cells. This highlights the need for careful monitoring of phase I safety trials for these new therapies. The use of inducible costimulatory domains, or incorporation of TLR TIRs within the CARs so TIR dimerization is driven by antigen-engagement, could mitigate against constitutive MyD88 activity. Safety measures of broad applicability to gene-modified cellular therapies include use of lategeneration lentiviral vectors with an established safety record, incorporation of 'safety switches' that can deplete gene-modified cells, and recipient enrolment to cellular therapy registries that capture rare or long-latency toxicities. ${ }^{116}$ Finally, the relative merits of employing MyD88 and TLR TIR domains within gene-modified T-cells, compared with costimulatory domains derived from Ig or TNFR superfamily members, are yet to be fully determined, and benefits of specific costimulatory domains may prove to be specific to the CAR T-cell target or to the malignancy being treated. ${ }^{110}$

\section{CONCLUDING REMARKS}

Since Janeway first demonstrated T-cell intrinsic expression of TLR4 in 1989, understanding of the critical role of TLRs within T-cells has expanded substantially. It is now clear that many TLRs can be expressed by, and are functional within, both human and murine T-cells. TLR agonists can lower the threshold for TCR activation, enhance T-cell proliferation and cytokine production, promote T-cell memory formation, and modify the suppressive functions of Tregs.

T-cell intrinsic TLR expression is essential for the full effects of some systemically-administered TLR ligands, including classes of agent that are in clinical trials as cancer immunotherapies. The observation that TLR stimulation can promote tumor growth in some circumstances emphasizes the need for caution when administering TLR agonists systemically. Careful selection of agonist and route of administration, informed by TLR expression in the tumor and its microenvironment, may be crucial. Furthermore, the effect of combining TLR ligands with existing T-cell-based cancer immunotherapies, particularly checkpoint blockade, needs to be clarified.

T-cell-intrinsic TLR signaling clearly plays a key role in the quality and longevity of adaptive immune responses. In previous studies, this fact has often been overlooked in favor of focusing on the functions of TLR signaling in innate immune cells, which typically express much higher levels of TLRs. The burgeoning field of gene-modified adoptive cell therapies, including CAR T-cells, affords a new opportunity to specifically trigger TLR signaling within T-cells. Further research will determine the safety and efficacy of TLR signaling domains in CAR T-cells, compared with other costimulatory domains. Based on an in-depth review of the literature along with our own experience, we conclude that the appreciation of both T-cell intrinsic and extrinsic effects of TLR signaling is essential for those planning, and interpreting the results of, clinical trials involving TLR-activating cancer immunotherapies.

Acknowledgements We wish to thank the Thompson Family Foundation and the Grady Grant for their generous sponsorship of the Malagahan Institute's CAR T-cell research programme, as well as the John and Margaret Hunn Education Trust for their support of Yasmin Nouri. Figures were created using BioRender.com.

Contributors RP and RW conceived the manuscript; YN, RP and RW wrote the manuscript; all authors approved the final manuscript.

Funding The authors received funding from the Health Research Council of New Zealand (grants 19-816 to RW and RP, and 19-139 to RW), Freemasons New Zealand, a research fellowship from the Keith \& Faith Taylor Charitable Trust (RP) and a PhD scholarship from Leukemia \& Blood Cancer New Zealand (YN).

Competing interests RP and RW are employees of the Malaghan Institute of Medical Research, a registered charity and sponsor of a trial of chimeric antigen receptor T-cells incorporating a TLR2-derived domain; none of the authors have a proprietary or intellectual property interest in the product; no other competing interests to declare.

Patient consent for publication Not applicable.

Provenance and peer review Not commissioned; externally peer reviewed.

Open access This is an open access article distributed in accordance with the Creative Commons Attribution Non Commercial (CC BY-NC 4.0) license, which permits others to distribute, remix, adapt, build upon this work non-commercially, and license their derivative works on different terms, provided the original work is properly cited, appropriate credit is given, any changes made indicated, and the use is non-commercial. See http://creativecommons.org/licenses/by-nc/4.0/.

ORCID iD

Rachel Perret http://orcid.org/0000-0003-1225-5097

\section{REFERENCES}

1 Coley WB. The treatment of malignant tumors by repeated inoculations of erysipelas. with a report of ten original cases. 1893. Clin Orthop Relat Res 1991:3-11.

2 Pearl R. Cancer and tuberculosis. Am J Epidemiol 1929;9:97-159.

3 Pettenati C, Ingersoll MA. Mechanisms of BCG immunotherapy and its outlook for bladder cancer. Nat Rev Urol 2018;15:615-25.

4 Jain N, Hubbard J, Vega F, et al. Spontaneous remission of acute myeloid leukemia: report of three cases and review of the literature. Clin Leuk 2008;2:64-7.

5 Janeway CA. Approaching the asymptote? Evolution and revolution in immunology. Cold Spring Harb Symp Quant Biol 1989;54:1-13.

6 Medzhitov R, Preston-Hurlburt P, Janeway CA. A human homologue of the Drosophila toll protein signals activation of adaptive immunity. Nature 1997;388:394-7.

7 Manicassamy S, Pulendran B. Modulation of adaptive immunity with Toll-like receptors. Semin Immunol 2009;21:185-93.

8 Takeda K, Kaisho T, Akira S. Toll-like receptors. Annu Rev Immunol 2003;21:335-76.

9 Kabelitz D. Expression and function of Toll-like receptors in T Iymphocytes. Curr Opin Immunol 2007;19:39-45.

10 Adams S. Toll-like receptor agonists in cancer therapy. Immunotherapy 2009;1:949-64.

11 Weng J, Lai P, Qin L, et al. A novel generation 1928zT2 CAR T cells induce remission in extramedullary relapse of acute lymphoblastic leukemia. J Hematol Oncol 2018;11.

12 Lai Y, Weng J, Wei X, et al. Toll-like receptor 2 costimulation potentiates the antitumor efficacy of CAR T cells. Leukemia 2018;32:801-8.

13 George P, Dasyam N, Giunti G, et al. Third-generation anti-CD19 chimeric antigen receptor T-cells incorporating a TLR2 domain for relapsed or refractory B-cell lymphoma: a phase I clinical trial protocol (ENABLE). BMJ Open 2020;10:e034629. 
14 Mata M, Gerken C, Nguyen P, et al. Inducible activation of MyD88 and CD40 in CAR T cells results in controllable and potent antitumor activity in preclinical solid tumor models. Cancer Discov 2017;7:1306-19.

15 Collinson-Pautz MR, Chang W-C, Lu A, et al. Constitutively active MyD88/CD40 costimulation enhances expansion and efficacy of chimeric antigen receptor T cells targeting hematological malignancies. Leukemia 2019;33:2195-207.

16 O'Neill LA, Dinarello CA. The IL-1 receptor/Toll-like receptor superfamily: crucial receptors for inflammation and host defense. Immunol Today 2000;21:206-9.

17 Botos I, Segal DM, Davies DR. The structural biology of Toll-like receptors. Structure 2011;19:447-59.

18 Anderson KV, Bokla L, Nüsslein-Volhard C. Establishment of dorsalventral polarity in the Drosophila embryo: the induction of polarity by the Toll gene product. Cell 1985;42:791-8.

19 Nie L, Cai S-Y, Shao J-Z, et al. Toll-Like receptors, associated biological roles, and signaling networks in non-mammals. Front Immunol 2018;9:1523.

20 Kawasaki T, Kawai T. Toll-like receptor signaling pathways. Front Immunol 2014;5:461.

21 West AP, Koblansky AA, Ghosh S. Recognition and signaling by tolllike receptors. Annu Rev Cell Dev Biol 2006;22:409-37.

$22 \mathrm{Xu} \mathrm{D}$, Liu H, Komai-Koma M. Direct and indirect role of Tolllike receptors in T cell mediated immunity. Cell Mol Immunol 2004;1:239-46.

23 Zähringer U, Lindner B, Inamura S, et al. TLR2 - promiscuous or specific? A critical re-evaluation of a receptor expressing apparent broad specificity. Immunobiology 2008;213:205-24.

24 Akira S. Mammalian Toll-like receptors. Curr Opin Immunol 2003;15:5-11.

25 Poltorak A, He X, Smirnova I, et al. Defective LPS signaling in $\mathrm{C} 3 \mathrm{H} /$ $\mathrm{HeJ}$ and C57BL/10ScCr mice: mutations in TLR4 gene. Science 1998:282:2085-8.

26 Hayashi F, Smith KD, Ozinsky A, et al. The innate immune response to bacterial flagellin is mediated by Toll-like receptor 5 . Nature 2001:410:1099-103.

27 Oosting M, Cheng S-C, Bolscher JM, et al. Human TLR10 is an anti-inflammatory pattern-recognition receptor. Proc Natl Acad Sci U S A 2014;111:E4478-84.

28 Barton GM, Kagan JC, Medzhitov R. Intracellular localization of Toll-like receptor 9 prevents recognition of self DNA but facilitates access to viral DNA. Nat Immunol 2006;7:49-56.

29 Lee HK, Lund JM, Ramanathan B, et al. Autophagy-dependent viral recognition by plasmacytoid dendritic cells. Science 2007;315:1398-401.

30 Nishiya T, Kajita E, Miwa S, et al. TLR3 and TLR7 are targeted to the same intracellular compartments by distinct regulatory elements. $J$ Biol Chem 2005;280:37107-17.

31 Alexopoulou L, Holt AC, Medzhitov R, et al. Recognition of doublestranded RNA and activation of NF- $\mathrm{kB}$ by toll-like receptor 3 . Nature 2001;413:732-8.

32 Heil F, Hemmi H, Hochrein $\mathrm{H}$, et al. Species-specific recognition of single-stranded RNA via till-like receptor 7 and 8 . Science 2004;303:1526-9.

33 Hemmi H, Takeuchi O, Kawai T, et al. A toll-like receptor recognizes bacterial DNA. Nature 2000;408:740-5.

34 Raetz M, Kibardin A, Sturge CR, et al. Cooperation of TLR12 and TLR11 in the IRF8-dependent IL-12 response to Toxoplasma gondii profilin. J Immunol 2013;191:4818-27.

35 Koblansky AA, Jankovic D, Oh $\mathrm{H}$, et al. Recognition of profilin by toll-like receptor 12 is critical for host resistance to Toxoplasma gondii. Immunity 2013;38:119-30.

36 Hatai H, Lepelley A, Zeng W, et al. Toll-like receptor 11 (TLR11) interacts with flagellin and profilin through disparate mechanisms. PLoS One 2016;11:e0148987.

37 Hidmark A, von Saint Paul A, Dalpke AH. Cutting edge: Tlr13 is a receptor for bacterial RNA. J Immunol 2012;189:2717-21.

38 Ozinsky A, Underhill DM, Fontenot JD, et al. The repertoire for pattern recognition of pathogens by the innate immune system is defined by cooperation between Toll-like receptors. Proc Natl Acad Sci U S A 2000;97:13766-71.

39 Horng T, Barton GM, Flavell RA, et al. The adaptor molecule TIRAP provides signalling specificity for Toll-like receptors. Nature 2002;420:329-33

40 Medzhitov R, Preston-Hurlburt P, Kopp E, et al. MyD88 is an adaptor protein in the $\mathrm{hToll} / \mathrm{IL}-1$ receptor family signaling pathways. Mol Cell 1998;2:253-8.

41 Rahman AH, Taylor DK, Turka LA. The contribution of direct TLR signaling to T cell responses. Immunol Res 2009;45:25-36.
42 O'Neill LAJ, Bowie AG. The family of five: TIR-domain-containing adaptors in Toll-like receptor signalling. Nat Rev Immunol 2007;7:353-64.

43 Kawai T, Akira S. Toll-like receptors and their crosstalk with other innate receptors in infection and immunity. Immunity 2011;34:637-50.

44 Imanishi T, Hara H, Suzuki S, et al. Cutting edge: TLR2 directly triggers Th1 effector functions. J Immunol 2007;178:6715-9.

45 Chapman NM, Bilal MY, Cruz-Orcutt N, et al. Distinct signaling pathways regulate TLR2 co-stimulatory function in human T cells. Cell Signal 2013;25:639-50.

46 Adib-Conquy M, Scott-Algara D, Cavaillon J-M, et al. TLRmediated activation of NK cells and their role in bacterial/ viral immune responses in mammals. Immunol Cell Biol 2014;92:256-62.

47 Hornung V, Rothenfusser S, Britsch S, et al. Quantitative expression of toll-like receptor 1-10 mRNA in cellular subsets of human peripheral blood mononuclear cells and sensitivity to $\mathrm{CpG}$ oligodeoxynucleotides. J Immunol 2002;168:4531-7.

48 Mansson A, Adner M, Cardell LO. Toll-like receptors in cellular subsets of human tonsil T cells: altered expression during recurrent tonsillitis. Respir Res 2006;7:36.

49 Caron G, Duluc D, Frémaux I, et al. Direct stimulation of human T cells via TLR5 and TLR7/8: flagellin and R-848 up-regulate proliferation and IFN- $\gamma$ production by memory CD4+ T cells. $J$ Immunol 2005;175:1551-7.

50 Crellin NK, Garcia RV, Hadisfar O, et al. Human CD4+ T cells express TLR5 and its ligand flagellin enhances the suppressive capacity and expression of FOXP3 in CD4+CD25+ T regulatory cells. J Immunol 2005;175:8051-9.

51 Komai-Koma M, Jones L, Ogg GS, et al. TLR2 is expressed on activated T cells as a costimulatory receptor. Proc Natl Acad Sci U S A 2004;101:3029-34.

52 Wesch D, Beetz S, Oberg H-H, et al. Direct costimulatory effect of TLR3 ligand poly(l:C) on human gamma delta T lymphocytes. $J$ Immunol 2006;176:1348-54.

53 Tabiasco J, Devêvre E, Rufer N, et al. Human effector CD8+ T lymphocytes express TLR3 as a functional coreceptor. J Immunol 2006;177:8708-13.

54 Tripathy A, Khanna S, Padhan P, et al. Direct recognition of LPS drive TLR4 expressing CD8+ T cell activation in patients with rheumatoid arthritis. Sci Rep 2017;7:1-10.

55 Cottalorda A, Verschelde C, Marçais A, et al. TLR2 engagement on CD8 T cells lowers the threshold for optimal antigen-induced T cell activation. Eur J Immunol 2006;36:1684-93.

56 Sobek V, Birkner N, Falk I, et al. Direct Toll-like receptor 2 mediated co-stimulation of T cells in the mouse system as a basis for chronic inflammatory joint disease. Arthritis Res Ther 2004;6:R433.

57 Gelman AE, Zhang J, Choi Y, et al. Toll-Like receptor ligands directly promote activated CD4+ T cell survival. J Immunol 2004:172:6065-73.

58 Caramalho I, Lopes-Carvalho T, Ostler D, et al. Regulatory T cells selectively express toll-like receptors and are activated by lipopolysaccharide. J Exp Med 2003;197:403-11.

59 Fukata M, Breglio K, Chen A, et al. The myeloid differentiation factor 88 (MyD88) is required for CD4+ T cell effector function in a murine model of inflammatory bowel disease. J Immunol 2008;180:1886-94.

60 Liu H, Komai-Koma M, Xu D, et al. Toll-Like receptor 2 signaling modulates the functions of CD4+CD25+ regulatory T cells. Proc Natl Acad Sci U S A 2006;103:7048-53.

61 Imanishi T, Unno M, Kobayashi W, et al. Mtorc1 signaling controls TLR2-mediated T-cell activation by inducing TIRAP expression. Cell Rep 2020;32:107911.

62 Chen L, Flies DB. Molecular mechanisms of T cell co-stimulation and co-inhibition. Nat Rev Immunol 2013;13:227-42.

63 Karim AF, Reba SM, Li Q, et al. Toll like receptor 2 engagement on $\mathrm{CD}^{+}{ }^{+} \mathrm{T}$ cells promotes TH9 differentiation and function. Eur $J$ Immunol 2017:47:1513-24.

64 Nyirenda MH, Sanvito L, Darlington PJ, et al. TLR2 stimulation drives human naive and effector regulatory $T$ cells into a Th17like phenotype with reduced suppressive function. $J$ Immunol 2011;187:2278-90.

65 Reynolds JM, Pappu BP, Peng J, et al. Toll-like receptor 2 signaling in CD4(+) T lymphocytes promotes T helper 17 responses and regulates the pathogenesis of autoimmune disease. Immunity 2010;32:692-702.

66 Krampera M, Tavecchia L, Benedetti F, et al. Intracellular cytokine profile of cord blood T-, and NK- cells and monocytes. Haematologica 2000;85:675-9. 
67 Chodisetti SB, Gowthaman U, Rai PK, et al. Triggering through toll-like receptor 2 limits chronically stimulated T-helper type 1 cells from undergoing exhaustion. J Infect Dis 2015;211:486-96.

68 McCarron M, Reen DJ. Activated human neonatal CD8+ T cells are subject to immunomodulation by direct TLR2 or TLR5 stimulation. $J$ Immunol 2009;182:55-62.

69 Mercier BC, Cottalorda A, Coupet C-A, et al. TLR2 engagement on CD8 T cells enables generation of functional memory cells in response to a suboptimal TCR signal. J Immunol 2009;182:1860-7.

70 Salerno F, Freen-van Heeren JJ, Guislain A, et al. Costimulation through TLR2 drives polyfunctional $\mathrm{CD}^{++} \mathrm{T}$ cell responses. $J$ Immunol 2019;202:714-23.

71 Quigley M, Martinez J, Huang X, et al. A critical role for direct TLR2-MyD88 signaling in CD8 T-cell clonal expansion and memory formation following vaccinia viral infection. Blood 2009;113:2256-64.

72 Li Q, Yan Y, Liu J, et al. Toll-Like receptor 7 activation enhances CD8+ T cell effector functions by promoting cellular glycolysis. Front Immunol 2019;10:2191.

73 Oberg H-H, Ly TTH, Ussat S, et al. Differential but direct abolishment of human regulatory $T$ cell suppressive capacity by various TLR2 ligands. J Immunol 2010;184:4733-40.

74 Netea MG, Sutmuller R, Hermann C, et al. Toll-like receptor 2 suppresses immunity against Candida albicans through induction of IL-10 and regulatory T cells. J Immunol 2004;172:3712-8.

75 Sutmuller RPM, den Brok MHMGM, Kramer M, et al. Toll-like receptor 2 controls expansion and function of regulatory T cells. $J$ Clin Invest 2006;116:485-94.

76 Sinnott BD, Park B, Boer MC, et al. Direct TLR-2 costimulation unmasks the proinflammatory potential of neonatal CD4+ T cells. $J$ Immunol 2016;197:68-77.

77 Kahler H, Shear MJ. Chemical treatment of tumors. VIII. ultracentrifugal and electrophoretic analysis of the hemorrhageproducing fraction from Serratia marcescens (Bacillus prodigiosus) culture filtrate. J Natl Cancer Inst 1943;4:123-9.

78 Garay RP, Viens P, Bauer J, et al. Cancer relapse under chemotherapy: why TLR2/4 receptor agonists can help. Eur $J$ Pharmacol 2007;563:1-17.

79 Burns CA, Brown MD. Imiquimod for the treatment of skin cancer. Dermatol Clin 2005;23:151-64

80 Krieg AM. Development of TLR9 agonists for cancer therapy. J Clin Invest 2007:117:1184-94.

81 Kiura K, Hasebe A, Saeki A, et al. In vivo anti- and protumour activities of the TLR2 ligand FSL-1. Immunobiology 2011;216:891-900.

82 Morales A, Eidinger D, Bruce AW. Intracavitary Bacillus CalmetteGuerin in the treatment of superficial bladder tumors. J Urol 1976;116:180-2.

83 Lamm DL, Thor DE, Harris SC, et al. Bacillus CalmetteGuerin immunotherapy of superficial bladder cancer. J Urol 1980;124:38-42.

84 Uehori J, Matsumoto M, Tsuji S, et al. Simultaneous blocking of human toll-like receptors 2 and 4 suppresses myeloid dendritic cell activation induced by Mycobacterium bovis bacillus CalmetteGuérin peptidoglycan. Infect Immun 2003;71:4238-49.

85 Perret R, Sierro SR, Botelho NK, et al. Adjuvants that improve the ratio of antigen-specific effector to regulatory $\mathrm{T}$ cells enhance tumor immunity. Cancer Res 2013;73:6597-608.

86 Lynn GM, Sedlik C, Baharom F, et al. Peptide-TLR-7/8a conjugate vaccines chemically programmed for nanoparticle self-assembly enhance CD8 T-cell immunity to tumor antigens. Nat Biotechnol 2020;38:320-32.

87 Lu BL, Williams GM, Verdon DJ, et al. Synthesis and evaluation of novel TLR2 agonists as potential adjuvants for cancer vaccines. $J$ Med Chem 2020;63:2282-91.

88 Zahm CD, Colluru VT, Mcllwain SJ, et al. TLR stimulation during T-cell activation lowers PD- 1 expression on $\mathrm{CD}^{++} \mathrm{T}$ cells. Cancer Immunol Res 2018;6:1364-74.

89 Zhang Y, Luo F, Cai Y, et al. TIr1/TIr2 agonist induces tumor regression by reciprocal modulation of effector and regulatory $T$ cells. J Immunol 2011;186:1963-9.

90 Zhang Y, Luo F, Li A, et al. Systemic injection of TLR1/2 agonist improves adoptive antigen-specific T cell therapy in glioma-bearing mice. Clin Immunol 2014:154:26-36.

91 Asprodites N, Zheng L, Geng D, et al. Engagement of toll-like receptor-2 on cytotoxic T-lymphocytes occurs in vivo and augments antitumor activity. Faseb J 2008;22:3628-37.
92 Geng D, Zheng L, Srivastava R, et al. Amplifying TLR-MyD88 signals within tumor-specific $T$ cells enhances antitumor activity to suboptimal levels of weakly immunogenic tumor antigens. Cancer Res 2010;70:7442-54.

93 Noh J-Y, Yoon SR, Kim T-D, et al. Toll-like receptors in natural killer cells and their application for immunotherapy. J Immunol Res 2020;2020:1-9.

94 Otto F, Schmid P, Mackensen A, et al. Phase II trial of intravenous endotoxin in patients with colorectal and non-small cell lung cancer. Eur J Cancer 1996;32A:1712-8.

95 Carpentier A, Laigle-Donadey F, Zohar S, et al. Phase 1 trial of a $\mathrm{CpG}$ oligodeoxynucleotide for patients with recurrent glioblastoma. Neuro Oncol 2006;8:60-6.

96 Stockfleth E, Trefzer U, Garcia-Bartels C, et al. The use of Toll-like receptor-7 agonist in the treatment of basal cell carcinoma: an overview. Br J Dermatol 2003;149:53-6.

97 Spaner DE, Masellis A. Toll-like receptor agonists in the treatment of chronic lymphocytic leukemia. Leukemia 2007;21:53-60.

98 Weigel BJ, Cooley S, DeFor T, et al. Prolonged subcutaneous administration of $852 \mathrm{~A}$, a novel systemic toll-like receptor 7 agonist, to activate innate immune responses in patients with advanced hematologic malignancies. Am J Hematol 2012;87:953-6.

99 Kaczanowska S, Joseph AM, Davila E. TLR agonists: our best frenemy in cancer immunotherapy. J Leukoc Biol 2013;93:847-63.

100 Urban-Wojciuk Z, Khan MM, Oyler BL, et al. The role of TLRs in anti-cancer immunity and tumor rejection. Front Immunol 2019;10:2388.

101 Karin M, Yamamoto Y, Wang QM. The IKK NF-Î'B system: a treasure trove for drug development. Nat Rev Drug Discov 2004;3:17-26.

102 Huang B, Zhao J, Shen S, et al. Listeria monocytogenes Promotes Tumor Growth via Tumor Cell Toll-Like Receptor 2 Signaling. Cancer Res 2007;67:4346-52.

103 Logunov DY, Scheblyakov DV, Zubkova OV, et al. Mycoplasma infection suppresses p53, activates NF-10 B and cooperates with oncogenic Ras in rodent fibroblast transformation. Oncogene 2008:27:4521-31

104 Kim S, Takahashi H, Lin W-W, et al. Carcinoma-produced factors activate myeloid cells through TLR2 to stimulate metastasis. Nature 2009;457:102-6.

105 Luo J-L, Maeda S, Hsu L-C, et al. Inhibition of NF-1̂º in cancer cells converts inflammation- induced tumor growth mediated by TNF $\alpha$ to TRAIL-mediated tumor regression. Cancer Cell 2004;6:297-305.

106 Harmey JH, Bucana CD, Lu W, et al. Lipopolysaccharide-induced metastatic growth is associated with increased angiogenesis, vascular permeability and tumor cell invasion. Int $J$ Cancer 2002;101:415-22.

107 Ilvesaro JM, Merrell MA, Swain TM, et al. Toll like receptor-9 agonists stimulate prostate cancer invasion in vitro. Prostate 2007;67:774-81.

108 Droemann D, Albrecht D, Gerdes J, et al. Human lung cancer cells express functionally active Toll-like receptor 9 . Respir Res 2005;6.

109 Kim WY, Lee J-W, Choi J-J, et al. Increased expression of Toll-like receptor 5 during progression of cervical neoplasia. Int $J$ Gynecol Cancer 2008;18:300-5.

110 Weinkove R, George P, Dasyam N, et al. Selecting costimulatory domains for chimeric antigen receptors: functional and clinical considerations. Clin Transl Immunol 2019;8:e1049.

111 Pang N, Shi J, Qin L, et al. IL-7 and CCL19-secreting CAR-T cell therapy for tumors with positive glypican-3 or mesothelin. $J$ Hematol Oncol 2021:14:118.

112 Kaczanowska S, Joseph AM, Guo J, et al. A synthetic CD8 $\alpha$ :MyD88 coreceptor enhances CD8 ${ }^{+}$T-cell responses to weakly immunogenic and lowly expressed tumor antigens. Cancer Res 2017;77:7049-58

113 Xie G, Dong H, Liang Y, et al. CAR-NK cells: a promising cellular immunotherapy for cancer. EBioMedicine 2020;59:102975.

114 Yu X, Li W, Deng Q, et al. MYD88 L265P mutation in lymphoid malignancies. Cancer Res 2018:78:2457-62.

115 Knittel G, Liedgens P, Korovkina D, et al. B-cell-specific conditional expression of Myd88p.L252P leads to the development of diffuse large B-cell lymphoma in mice. Blood 2016;127:2732-41.

116 Milone MC, O'Doherty U. Clinical use of lentiviral vectors. Leukemia 2018:32:1529-41. 